\title{
Magellanic penguin (Spheniscidae) monitoring results for Magdalena island (Chile) and cabo Virgenes (Argentina): 2000 - 2019
}

\author{
Resultados de los estudios de pingüinos de Magallanes (Spheniscidae) en \\ isla Magdalena (Chile) y cabo Virgenes (Argentina) 2000 - 2019
}

Mike Bingham ${ }^{1 凶}$

\begin{abstract}
Magellanic penguins (Spheniscus magellanicus) are found only in South America, with breeding populations in Chile, Argentina and the Falklands (Malvinas). On Magdalena Island an initial increase in population $(59,000$ pairs in $2000 / 01$ to 63,000 pairs in 2008/2009) was followed by a population decline (to 43,000 pairs in $2018 / 19$ ) following a severe drought during 2009 that has left much of the island less suitable for nesting in burrows. The nearby colony situated in Argentina between the lighthouses of Cabo Virgenes and Punta Dungeness has increased in population from 122,000 pairs in $2008 / 09$ to 146,000 pairs in $2018 / 19$. It is likely that this increase is a result of penguins leaving Magdalena Island. Penguins nesting alongside the tourist path showed a reduction in predation and an increase in breeding success.
\end{abstract}

Key words:

Magellanic penguins, Spheniscus magellanicus, Magdalena Island, Strait of Magellan.

\section{Resumen}

Los pingüinos de Magallanes (Spheniscus magellanicus Forster, 1781) se encuentran sólo en Sudamérica, con poblaciones reproductivas en Chile, Argentina y las islas Malvinas (Falklands). En Chile una colonia importante de pingüinos de Magallanes está situado en la isla Magdalena, en el estrecho de Magallanes. Luego de un aumento de la población (59,000 parejas en 2000/01 a 63,000 parejas en 2008/09) la colonia ha sufrido una disminución de la población desde 2009 a
43,000 parejas en 2018/19, consecuencia de la perdida de la vegetación provocada por una severa sequia durante 2009. En Argentina una colonia importante de pingüinos de Magallanes está situado entre los faros de Cabo Virgenes (Argentina) y Punta Dungeness (Chile) en el estrecho de Magallanes. La colonia aumentó desde 122,000 parejas en 2008/09 hasta 146,000 parejas en $2018 / 19$, parcialmente por causa de un ingreso de pingüinos desde isla Magdalena. Los pingüinos nidificando al lado del sendero turistico registran una reducción en predación y un amuento en exito de reproducción.

\section{Palabras clave:}

pingüinos de Magallanes,

Spheniscus magellanicus, isla Magdalena, estrecho de Magallanes.

\section{INTRODUCTION}

Magellanic penguins (Spheniscus magellanicus) are found only in southern South America, with breeding populations in Chile, Argentina and the Falklands (Malvinas). Population studies estimate that the world population of Magellanic penguins is between 1.3 and 1.7 million breeding pairs, with approximately 700,000 pairs in Chile, 900,000 pairs in Argentina and 100,000 pairs in the Falklands (Bingham \& Herrmann,

\footnotetext{
Environmental Research Unit,

Casilla 263, Punta Arenas, Chile.

\mbingham@penguins.cl
} 
2009; Falabella \& Campagna, 2019).

Population studies in the Falklands have shown a $92 \%$ decline in Magellanic penguins between 1990/91 and 2018/19 (Ellis et al. 1996; Bingham 2002; Falabella \& Campagna, 2019). Removal of fish and squid by the Falklands commercial fishing industry established in 1988 is the principal cause of the Falklands decline, making it difficult for adults to find sufficient food for their chicks, causing high chick mortality, which in turn has led to a lack of recruitment to replace penguins dying from old age. The evidence and mechanism of this decline is outlined in detail in Bingham (2002).

Population studies at the Provincial Reserve Cabo Vírgenes (Argentina) indicate a population of 146,000 reproductive pairs in 2018/19 (Fig. 1). Cabo Virgenes is open to the public but visitor numbers are low and there are no tour operators visiting the colony. The nearest town of Rio Gallegos is small and has little tourism, so visitors to the colony are mostly local. Access to the colony is by vehicle along a severely degraded dirt track that is 115 kilometres long, and more suited to offroad vehicles than cars, so visitor numbers are low, averaging about 30 per week during 2019.

One of the largest and most important breeding sites for Magellanic penguins in Chile is located on Magdalena Island in the Straits of Magellan
(Fig. 1). In 1966 the island was declared a Natural Monument due to its importance as a breeding site for the species, and is managed by CONAF (Corporación Nacional Forestal). Magdalena Island is a popular tourist destination, with an average of 2,500 tourists visiting the island each week during 2018. The tourists arrive by boat in groups of up to several hundred at a time, and follow a set path around the island. Tourists are allowed just one hour ashore by the tour operators, and are accompanied by professional guides. Penguins have an average of two or three visits per day during which people are walking along the path, with a complete absence of tourists between these visits. Hundreds of people in Punta Arenas are directly and indirectly employed by tourism on Magdalena Island.

The aim of this study is to monitor the effects of tourism on the reproduction and survival of penguins at both Magdalena Island and Cabo Virgenes, and to ensure the sustainable use of these reserves as a tourist resource. The study also aims to monitor population trends at these locations and to identify any other problems that may impact on the penguins.

\section{MATERIALS AND METHODS}

Because Magellanic penguins live below ground in burrows, and over such a large area,

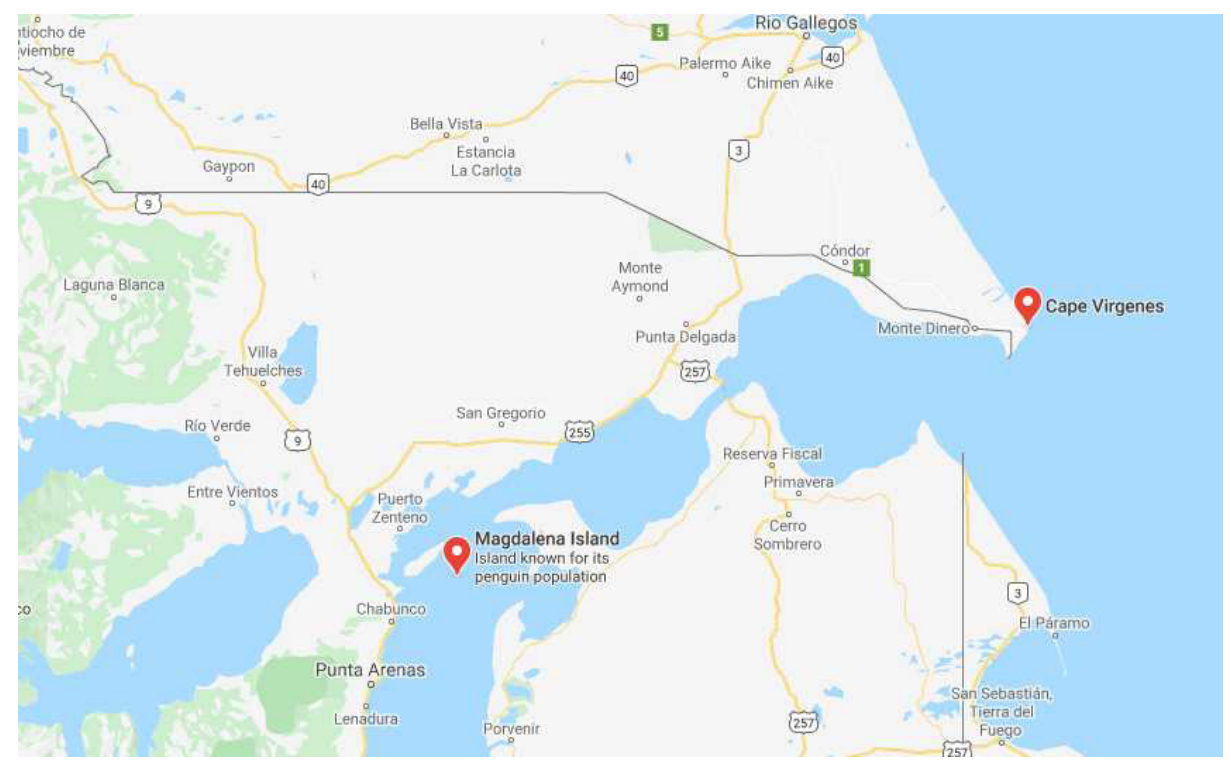

Fig. 1. Study area. Cartography: (c) Mike Bingham, Organization for the Conservation of Penguins, 2019 
direct nest counts are not possible. Many burrows are unoccupied, or are occupied by non-breeding single adults, so to assume that all burrows contain nests would greatly over-estimate the population size. To count breeding pairs it is necessary to look inside each burrow to confirm the presence of eggs shortly after laying. For Magellanic penguins it is necessary to establish fixed study plots to obtain long-term population data (Hiscock, 1993; Bingham, 2004; Bingham \& Herrmann, 2009).

In December 1998, studies began on Magdalena Island to determine the number of plots required for an island with such a varied terrain and soil type. Habitat maps were prepared, along with a population census of all bird species found on the island (Bingham \& Herrmann, 2009).

With funding from the British government, seven fixed study-plots were established on Magdalena Island in 1999 to estimate penguin population trends, six plots of 50 metres by 50 metres, and one plot of 30 metres by 100 metres. Every single burrow within these plots was examined each year in late October to determine the number of occupied nests, and this was used to estimate the average breeding density in nests per square metre. The nesting area was also mapped out by GPS, and multiplying the breeding area of the island in square metres, by the average number of nests per square metre, an estimate of the island's population size was obtained.

The greatest margin of error in determining population size using this method is in the assumption that breeding density recorded in the plots is representative of the entire island, but by using permanent study plots year after year, this margin for error is eliminated when looking for changes in population size. Even minor changes in breeding density, and hence population size and trends, can be measured with accuracy using permanent study plots, even though a greater margin of error is implied when extending this to defining an actual population size in any particular year (Hiscock, 1993).

In addition to studying population changes, in late October, shortly after egg-laying, around 20 occupied nests in each plot were marked, and these nests were visited regularly throughout the season, to determine what proportion of eggs hatch, how many chicks survive to leave the nest, the major causes of egg and chick loss, and chick weight. In addition to the seven study plots, occupied nests alongside the tourist path were also marked and studied, to look for differences in breeding success and chick survival rates resulting from the presence of large numbers of tourists.

The same methodology was employed to study Magellanic penguin populations at Cabo Vírgenes since 2003 (Fig. 1). Unlike Magdalena Island, Cabo Virgenes has dense thorn bushes, and the penguins nest above ground underneath the bushes instead of making burrows. Five fixed plots of 50 metres by 50 metres were used at Cabo Virgenes where the terrain is much more uniform and there is much less variation in nesting density. Nests alongside the tourist path were also marked and studied to look for differences caused by the presence of visitors.

\section{RESULTS}

\section{Magdalena Island colony}

Seven fixed study-plots were established on Magdalena Island to estimate penguin population trends. These plots indicated populations of 59,000 breeding pairs in 2000/01, 63,000 pairs in 2008/09, and 43,000 pairs in 2018/19 (Table 1).

Magellanic penguins make their nests in burrows on Magdalena Island. Prior to the drought of 2009 penguins nested over almost the entire island, so population increases could not occur as a result of increases in nesting area, only through increases in nesting density, which is limited for penguins that nest in burrows. The island had short grass with deep roots that stabilised the soil enough to support burrows over most of the island. In 2009 and 2010 the island suffered a severe drought that killed off all the vegetation leaving just bare soil. Without vegetation, the wind caused loose soil to be blown across the island (Fig. 2), covering and burying burrows, eggs and chicks (Fig. 3). This caused very low breeding success, and reduced the available nesting area of the island. The vegetation is now recovering over much of the island, however despite the return of vegetation, many areas still have soil below the surface that is too sandy and unstable to support the construction of burrows, reducing both the available nesting area and the nesting density of the colony. 
Table 1. Magellanic Penguin Population on Magdalena Island - 2000/01 to 2018/19 (Number of Occupied Nests)*.

\begin{tabular}{ccccc}
\hline Plot & $2000 / 01$ & $2008 / 09$ & $2019 / 19$ & Change \\
\hline 1 & 254 & 264 & 105 & $-60 \%$ \\
2 & 151 & 171 & 140 & $-20 \%$ \\
3 & 192 & 240 & 190 & $-20 \%$ \\
4 & 222 & 270 & 160 & $-40 \%$ \\
5 & 259 & 277 & 140 & $-50 \%$ \\
6 & 37 & 51 & 60 & $+20 \%$ \\
7 & 145 & 175 & 190 & $+10 \%$ \\
\hline Population & 59,000 & 63,000 & 43,000 & \\
\hline
\end{tabular}

(* Bingham \& Herrmann, 2008).

During 2018/19 a comparison of the fixed plots indicated large population changes since 2008/09. Five of the seven plots showed a decline in the number of occupied nests, ranging from $-20 \%$ to $-60 \%$ (Table 1). However an increase of 10 to $20 \%$ in the number of occupied nests was observed in two plots (Table 1). The majority of the decline on Magdalena has occurred in the flat valleys, with the hills showing a slight increase in population.

Plots 1, 4 and 5 are all very similar except for their location. They are all located in flat valleys where the worst of the drought occurred. The loss of almost all the vegetation on the island during the 2009-10 drought caused the wind to lift loose soil and deposit it in these valleys and plains, filling up the burrows, covering the nests, and causing the loss of many burrows. These areas are now covered with fine dusty soil underneath a shallow layer of new vegetation, with a labyrinth of voids below the surface because of the abandoned burrows that were buried.

These areas are no longer very suitable for building new burrows because the burrows collapse too easily. These three plots have registered the highest population decreases on the island. Plots 1 and 5 are linked by the large valley located between the lighthouse and the jetty, while Plot 4 is located

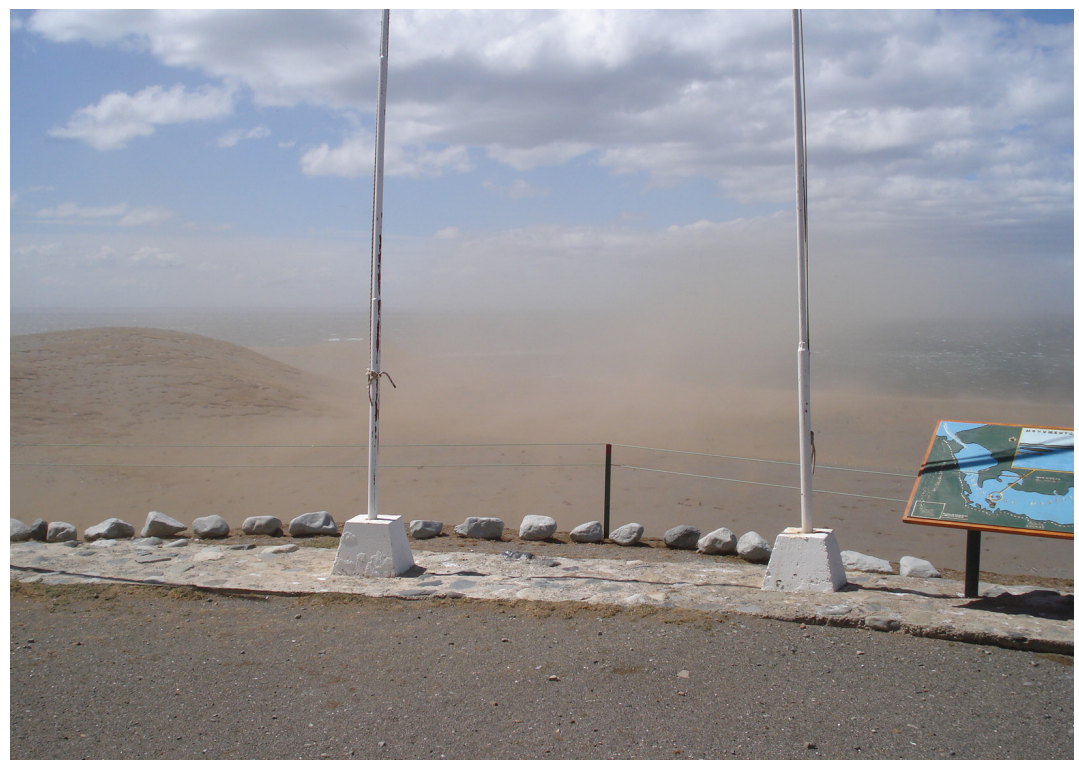

Fig. 2. Photo showing dust storms provoked by loss of vegetation after drought of 2009. Photo: (C) Mike Bingham, Organization for the Conservation of Penguins, 2011. 


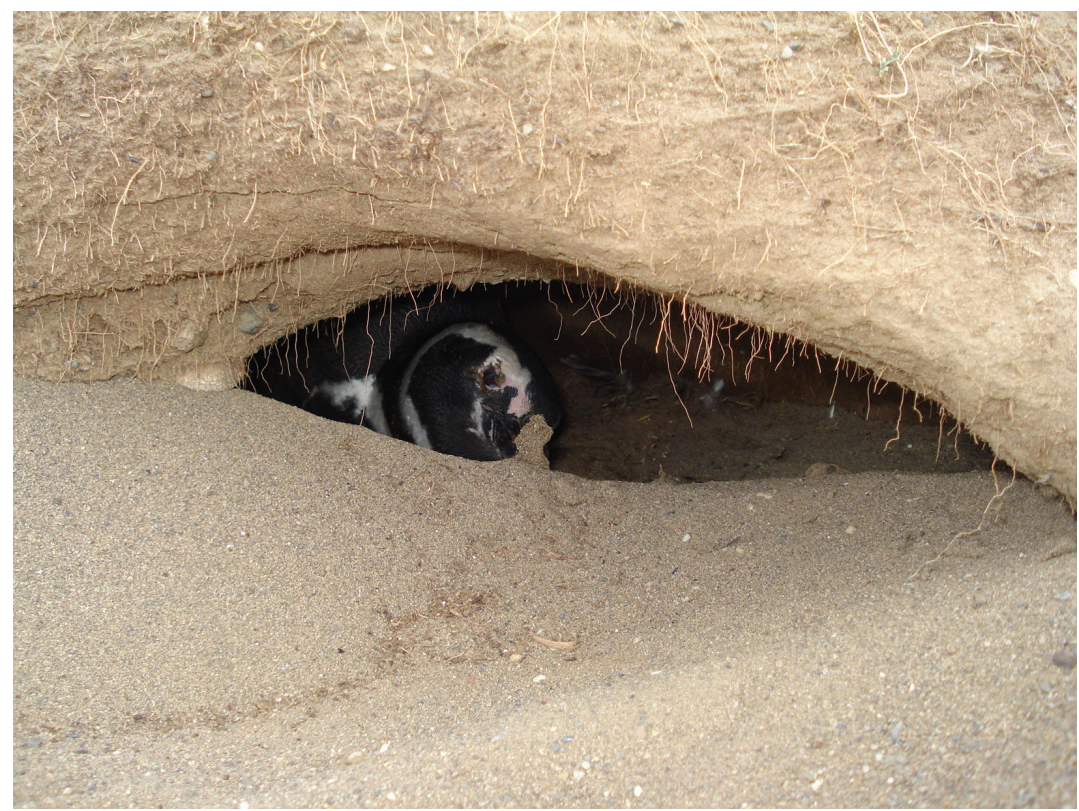

Fig. 3. Photo showing penguin burrows being buried by loose soil during dust storms. Photo: (c) Mike Bingham, Organization for the Conservation of Penguins, 2011.

on the opposite side of the island where tourists never visit. The plots were chosen to observe differences caused by the presence and absence of tourism in these types of flat terrain.

Plots 2 and 3 are also very similar to each other. Despite being flat these areas have firmer soil and better vegetation, making them more suitable for burrows. Plot 2 is exposed to low presence of tourists while Plot 3 has zero contact with tourism. The decrease in penguins is much lower in both these areas.

Plots 6 and 7 are both on top of hills and both are very similar in terrain, slope and aspect. They are on opposite sides of the island. Plot 6 has zero contact with tourism, while Plot 7 has tourists crossing between the plot and its access to the sea. However both plots have registered an increase in population.

During 2018/19 the mean breeding success on Magdalena Island was 0.74 chicks per nest (range $=0.34$ to 1.60 ), which indicates that $37 \%$ of all eggs laid survived to produce a juvenile that left the nest successfully (Table 2). Compared to that figure for the island as a whole, nests placed within two meters of the tourist path had a breeding success of 1.18 chicks per nest, which indicates that $59 \%$ of eggs placed very close to tourists survived. Nests within 2 metres of the tourists were $50 \%$ more successful than nests situated well away from tourists (Table 2).

This breeding success of 1.18 chicks per nest observed near to the tourist path is not only high for $2018 / 19$, it is also high compared to any year for Magdalena in general. Excluding the tourist path, Magdalena Island has not had breeding success of 1.18 in any plot since 2007/08 which was before the drought (Table 2).

Plot 1 is directly located below the lighthouse and is the plot with the highest presence of tourists compared to any other plot on the island. Despite suffering a reduction in nesting density since the drought, during 2018/19 the penguins remaining in Plot 1 had the highest breeding success on the entire island by far. Plot 1 was $60 \%$ more successful than any other plot on the island, with an average of 1.6 chicks per nest. A breeding success of 1.6 chicks per nest is exceptional, so exceptional that in 20 years of studies on Magdalena Island only penguins nesting alongside the tourist path have ever registered such a high level of breeding success.

During 2018/19 the breeding success in Plot 1 was more than double the average for the entire island, and raised more chicks per nest than 
Table 2. Magdalena Island nest analysis - 2018/19.

\begin{tabular}{cccccccc}
\hline Plots & Nests & Eggs & Eggs Lost (\%) & Lost Hatching (\%) & Chicks Lost (\%) & Fledged (\%) & Fledged per Nest \\
\hline 1 & 10 & 20 & 10 & 0 & 10 & 80 & 1.60 \\
2 & 14 & 28 & 14 & 7 & 36 & 43 & 0.86 \\
3 & 12 & 24 & 42 & 8 & 33 & 17 & 0.34 \\
4 & 10 & 20 & 30 & 5 & 40 & 25 & 0.50 \\
5 & - & - & - & - & - & - & - \\
6 & 12 & 24 & 38 & 4 & 33 & 25 & 0.50 \\
7 & 11 & 22 & 9 & 5 & 50 & 36 & 0.72 \\
Mean & & & 24 & 5 & 34 & 37 & 0.74 \\
\hline Path & 17 & 34 & 32 & 3 & 6 & 59 & 1.18 \\
\hline
\end{tabular}

*Plot 5 removed from breeding study in 2014 when tourist path was redirected through it.

any other plot during the 20 year study period. By comparison, the plots located in areas with zero contact with tourists had the lowest breeding success ( 0.5 chicks per nest or less).

\section{Cabo Virgenes colony}

The Magellanic penguin population at Cabo Virgenes has increased by $20 \%$ during the last 10 years, from 122,000 pairs in 2008/09 to 146,000 pairs in $2018 / 19$. With very few tourists visiting the colony there is no significant difference in breeding success between penguins alongside the tourist path and penguins well away from tourists. The colony at Cabo Virgenes appears to be in good health.

\section{DISCUSSION}

Magellanic penguins are only found in Argentina, Chile and the Falklands. Population studies are being carried out in all three countries using the same methodology of fixed study plots.

Small colonies of Magellanic penguins can be counted nest by nest, but a direct count is impossible for large colonies such as Cabo Virgenes and Magdalena Island. In such cases it is necessary to calculate the size of the population by plotting the total area of the colony, and multiplying this area by the density of nests per square meter determined by study plots.

According to the criterion given above and the errors inherent in the use of an average nesting density instead of direct counts, the population totals obtained using the aforementioned methodology have a margin of error of plus or minus $20 \%$. There are several methods available to obtain a single population estimate of Magellanic penguins, but only direct counts of every nest can reduce this margin of error. If the objective is to monitor population changes, or compare two or more censuses separated by time, then fixed plots is the only method available for large colonies. Fixed plots allow the precision of direct counts in small areas within the colony.

The use of fixed plots has a margin of error comparable with any other methodology when estimating population size, but with the advantage that using fixed plots eliminates the margin of error when estimating changes in population. Even small population changes can be detected using fixed plots. Other methods of estimating Magellanic penguin populations re-introduce the margin of error with each new count, eliminating any possibility of detecting changes smaller than the combined margin of error of any two counts.

To explain this in layman's terms, imagine throwing grains of rice onto a large table. Time does not allow each grain to be counted, so instead small squares (study plots) placed randomly across the table can estimate the amount of grains on the table. The estimate will obviously have a large margin of error because it assumes that the density in the squares is representative of the whole table. If the squares are fixed the same result will be recorded each time that the count is repeated. If someone later 
threw some additional grains onto the table, some additional grains would fall into the squares and the increase would be detected.

If the squares were not fixed, or if other methodology was employed such as transects running across the table at random, the count will be different each time it is repeated, even if the grains on the table have not changed. If the methodology gives different results each time it is repeated, then it is clearly impossible to use such a method to detect small changes.

Long-term population studies using fixed plots began in the Falklands in 1989 (Bingham, 2002), on Magdalena Island in 1998, and at Cabo Virgenes in 2003.

The decline of penguins on Magdalena Island is worrying at a local level, but does not indicate a decline at a regional level. At a regional level Magellanic penguins have shown a very slight and statistically insignificant increase over recent years. The increase of 24,000 pairs at Cabo Vírgenes is greater than the loss observed on Magdalena Island during the same period, and it is likely that Cabo Virgenes has benefited from an influx of penguins coming from Magdalena Island. Adding together both colonies gives a population of 185,000 pairs during 2008/09 and 189,000 pairs in 2018/19, an increase of 4,000 pairs over the last 10 years, so the regional population as a whole is healthy and stable.

At Cabo Virgenes the soil is not suitable for burrows, but the area is covered by thorn bushes which the penguins use as protection instead of burrows. There are no bushes at all on Magdalena Island, so without soil suitable for burrows the penguins are left exposed to predators and the weather, forcing them to look elsewhere to breed.

Magdalena Island and Cabo Virgenes are both located in maritime areas that are protected from large-scale commercial fishing by nofishing zones. Penguins at these sites can usually find plenty of food to feed their chicks, with the exception of during climatic events such as El Niño and La Niña. Penguin populations are tolerant of many problems if food remains abundant.

Magellanic penguin populations on the Falklands have declined by $92 \%$ from 1,300,000 pairs in 1990 (Ellis et al. 1996) to about 100,000 pairs in 2018 (Falabella \& Campagna, 2019). This decline is due to competition for food resources with the commercial fishing industry (Bingham, 2002). In September 2000 the participants of the Spheniscus Penguin Conservation Workshop held at La Serena (Chile) signed a petition calling on the Falkland Islands Government to establish no-fishing zones around penguin colonies, but that protection has still not been provided, and the penguin population continues to decline (Bingham, 2002; Luna et al. 2002; Falabella \& Campagna, 2019).

Penguins on Magdalena Island have declined for different reasons. Current data indicate that tourism is not the cause of the decline, and even has a minor role in improving breeding success for a few hundred penguins nesting alongside the tourist path.

The data indicate that penguins nesting in the presence of tourists have higher breeding success than other penguins on the island. During 2018/19 penguins most exposed to tourism had a $50 \%$ higher breeding success than the rest of the island. The same was recorded during 2005/06 and 2008/09. In 2009/10 and $2012 / 13$ the penguins closest to tourists recorded a 30\% higher breeding success, and on many other occasions the penguins most exposed to tourism recorded superior breeding success of less than $30 \%$ higher (Table 3 ).

The main predator of penguin chicks on Magdalena Island is the Skua (Stercorarius chilensis). The skua is very shy and avoids areas frequented by tourists. A reduction in the abundance of the skua decreases the mortality of chicks and increases the breeding success of the penguins. The data for Magdalena Island indicate that penguins raise more chicks and suffer less mortality of eggs and chicks in the presence of tourists, because the presence of tourists reduces the level of predation by skuas.

One of the main threats to Magdalena Island is the reduction of rainfall necessary to maintain vegetation in order to stabilise the soil so that penguins can dig burrows. The drought that occurred on Magdalena Island in 2009 seems to have been an unusual phenomenon. Before the drought the vegetation mostly comprised of grass species, but following the drought the recolonisation has largely begun with small groundhugging flowering plants. If the drought was a cyclic 


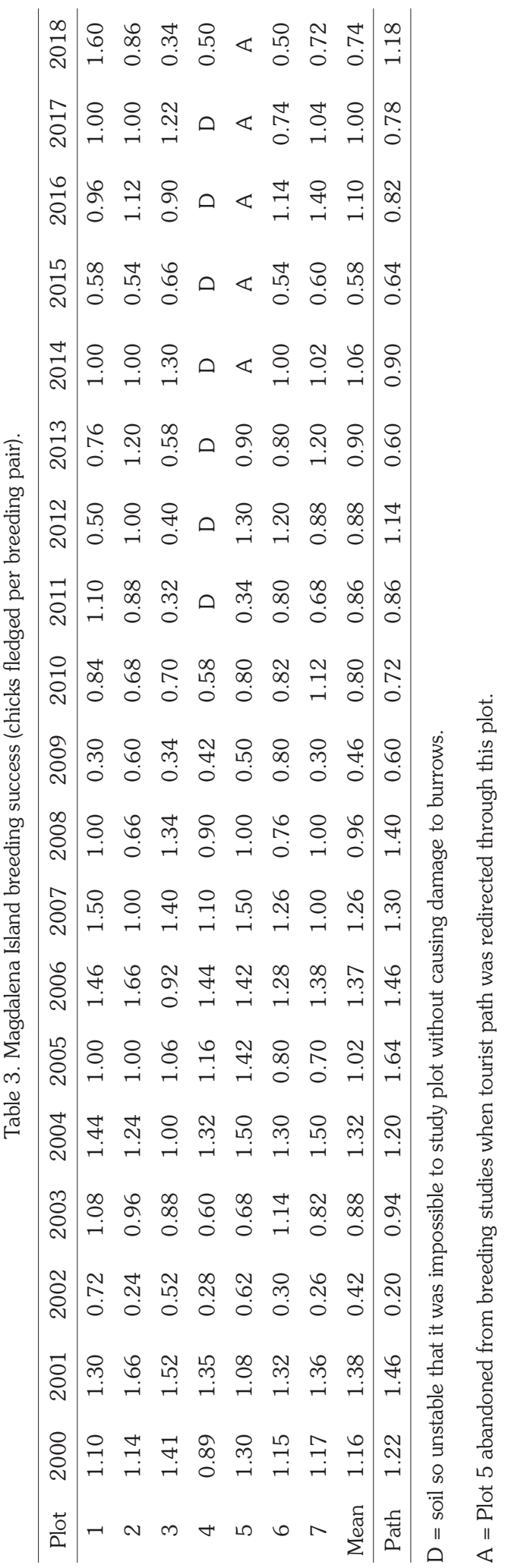

event occurring every 20 years for example, then major changes in vegetation composition would seem unlikely. The change in vegetation indicates that the drought was an unusual event and a link to climate change is a strong possibility.

Even though the vegetation has started to return on much of Magdalena Island, in many areas the number of penguins has continued to decline. The new vegetation has not established the deep roots that the original vegetation had, and the soil underneath is still sandy and collapses easily when penguins try to make burrows. The low-lying valleys are the most seriously affected because these are the areas where dust storms following the drought deposited thick layers of dry dusty soil which collapses too easily to support burrows. Until such time as the vegetation can stabilise these areas the penguin population on Magdalena Island is likely to continue declining.

\section{ACKNOWLEDGEMENTS}

My special thanks go to the Chilean National Forestry Corporation (CONAF) and the Consejo Agrario Provincial (CAP), for their help and hospitality. I am also very grateful to the crews of Melinka, Solo Expediciones, Australis, Fueguino, Don Jorge, Hundy and Mandamiento for their logistical support getting me to and from the island. I would like to thank my research assistants Noelia Reineck, Cici Legoe, Christopher Burney, Jennifer Rock, Jon Philipsborne, Joseph Brandt, Nidia Mendez and Elena Mejias. My special thanks to the British Government's Department for Environment, Food and Rural Affairs for funding the creation of this project through their Darwin Initiative Program.

\section{LITERATURE CITED}

Bingham, M. (2002). The decline of Falklands penguins in the presence of a commercial fishing industry. Revista Chilena de Historia Natural, 75, 805-818.

Bingham, M. (2004). Manual of instruction for monitoring of seabirds in Isla Magdalena. Report for CONAF.

Bingham, M., \& Herrmann, T. (2008). Results of the Magellanic Penguin studies on Isla 
Magdalena (Chile) 2000 - 2008. Anales Patagonian Sea.

Instituto del Instituto de la Patagonia, Hiscock, K. (1993). A manual for marine 36(2), 19-32.

Ellis, S., Croxall, J., \& Cooper, J. (Eds) (1996). Penguin Conservation Assessment biological inventory surveys. Joint Nature Conservation Committee Report MNCR / and Management Plan IUCN/SSC Conservation Breeding Specialist Group.

Falabella, V., \& Campagna, C. (Eds) (2019). Forum for the conservation of the Patagonian Sea 2019. Report of the IUCN Regional Red List First Workshop for species of the OR/ 19.

Luna, G., Hennicke, J., Wallace, R., Simeone, A., Wolfaardt A., Whittington P.,... \& McGovern, M. (Eds) (2002). Spheniscus Penguin Conservation Workgroup Report, IUCN/SSC Conservation Breeding Specialist Group. 